\title{
СОСТОЯНИЕ И ПЕРСПЕКТИВЫ РАЗВИТИЯ АУДИТА ЭФФЕКТИВНОСТИ В КИТАЙСКОЙ НАРОДНОЙ РЕСПУБЛИКЕ
}

\section{STATE AND PROSPECTS FOR THE DEVELOPMENT OF PERFORMANCE AUDIT IN CHINA}

Liu Yali

Summary: In the context of the continuous development of the economy in China and the accelerated pace of administrative reform, performance auditing is also an important means of assessing the efficiency of public resource allocation and assessing government performance. This paper examines the definition, characteristics, content, objectives and practical significance of public performance auditing, and conclusion that there are problems with the current performance audit in China: the establishment of the performance audit system is slow, the content of the performance audit is too narrow, the performance audit scorecard is imperfect. To solve these problems, the performance audit in China must update the concept of performance and improve technical methods, formulate a system of indicators for evaluating performance audits and improve local government laws and regulations on performance audits.

Keywords: performance audit, state audit, efficiency mark, specifications, measures.

\author{
Лю Яли \\ аспирант, Санкт-Петербургский государственный \\ университет \\ 18193158922@163.com
}

Аннотация: В условиях непрерывного роста экономики Китайской Народной Республики (КНР) и энергично проводящейся в КНР административной реформы аудит эффективности становится действенным инструментом оценки оптимальности распределения государственных ресурсов и важным способом контроля продуктивности работы правительства страны. В данной статье исследуются понятие, характеристики, содержание, цели и практическая значимость государственного аудита эффективности, а также делается вывод 0 том, что в настоящее время аудит эффективности в Китае находится в стадии становления, что обусловливает наличие ряда проблем. Так, формирование системы аудита эффективности происходит замедленными темпами, его оценочное содержание все еще носит ограниченный характер, а система показателей требует дальнейшего совершенствования и доработки. Для преодоления всех этих «болезней роста» аудита эффективности в КНР требуется обновление базовой концепции эффективности и модернизация методики его применения. Кроме того, следует оптимизировать систему показателей оценки аудита эффективности, а также усовершенствовать законодательство об аудите эффективности, относящееся к компетенции органов местного самоуправления КНР.

Ключевые слова: аудит эффективности, государственный аудит, оценка эффективности, характеристики, меры.

его исследования показали, что государственный аудит эффективности является сдерживающим фактором по отношению к росту долговой нагрузки провинций ${ }^{2}$.

\section{Определение и характеристика аудита эффективности}

Определение аудита эффективности. Как известно, аудит эффективности в качестве самостоятельного научного понятия оформился заметно позднее по сравнению с финансовым аудитом. В каком-то смысле эти понятия, разумеется, являются родственными, но, если говорить о специфических чертах собственно аудита эффективности, то, по мнению Вэй Хунчжэна, аудит эффективности - закономерный результат развития теории государственной фидуциарной ответственности, он отвечает за надзор, проверку и оценку экономичности, продуктивности и результативности бюджетных доховинции КНР в промежутке с 2005 по 2016 гг. Результаты

Ван Гуанюань (王光远), Чжэн Сяоюй (郑晓宇). 政府审计移送对司法效率的影响 / Влияние передачи государственного аудита на эффективность судебной системы // Исследование аудита. 2019(4). С. 11-19.

2 Ма Дуншань (马东山), Хань Лянлян (韩亮亮), Чжан Шэнцян (张胜强). Государственный аудит может уменьшить задолженность местных органов власти. Рост - перспектива фискальной децентрализации = 政府审计能够抑制地方政府债务增长吗? - 财政分权的视 角 // Аудит и экономические исследования. 2019 (4). С. 9-21. 
дов и расходов. Аналогичная ситуация складывается и в отношении связи между понятиями «аудит эффективности» и «оценка эффективности», здесь также имеют место и определенные различия ${ }^{3}$ и общие черты. Так, и то и другое понятие концентрируются на повышении эффективности использования бюджетных расходов; при этом их стандарты оценки эффективности в основном схожи. Что же касается различий, то аудит эффективности - это функция системы надзора, он фокусируется на микрооптимизации, а оценка эффективности решает свои задачи в большей степени на макроуровне. Предметы исследования оценки эффективности могут быть разнообразными, в то время как предмет исследования аудита эффективности, по существу, един - деятельность по использованию государственных ресурсов.

Бывший генеральный аудитор Китайской Народной Республики Лю Цзяи определил аудит эффективности как проверку, анализ и оценку результатов деятельности правительства (включая исполнение им обязанностей по отношению к обществу) независимыми аудиторскими учреждениями и аудиторами в соответствии с законодательством и нормативными актами, а также оценку рациональности, эффективности и научности использования социальных и экономических ресурсов государства. Иными словами, миссия аудита эффективности как контрольной процедуры состоит в том, чтобы способствовать всестороннему, скоординированному, эффективному и устойчивому социально-экономическому развитию государства.

Поскольку аудит эффективности представляет собой вид деятельности по проверке и оценке результатов деятельности правительства страны, то его объектами могут выступать различные виды экономической деятельности правительства, государственных ведомств и организаций. То есть аудит эффективности определяет степень экономичности, продуктивности и результативности экономической деятельности именно правительства, ведомств и других госучреждений.

Экономичность подразумевает использование наименьшего количества ресурсов (материальных, трудовых, энергетических, финансовых и пр.) для получения определенного количества (и качества!) продуктов или услуг и других результатов.

Продуктивность характеризует соотношение объема вложенных ресурсов (затрат «на входе» в экономическую модель) и полученных на основе этих ресурсов результатов («выхода»), имея в виду максимизацию «выхода» при заданном «входе».
Результативность, с одной стороны, показывает степень соответствия фактических результатов деятельности объекта аудита запланированным показателям, а с другой - характеризует социально-экономический эффект, получаемый от этих результатов.

Характеристика аудита эффективности. Являясь высшей формой аудиторской деятельности, аудит эффективности характеризуется следующими свойствами:

- различием стандартов аудиторской оценки. Вопервых, для КНР - государства, обладающего обширными территориями и богатыми ресурсами, свойственны существенные различия в уровне развития отдельных регионов, что обусловлено историческими и объективными факторами. Региональные различия естественным образом приводят к дифференцированной государственной политике и уровню социального развития в разных территориях. Во-вторых, предметы аудита могут отличаться, и, следовательно, стандарты оценки также будут различными;

- непрерывностью процесса аудита. Непрерывность процесса аудита эффективности в основном отражается в проектах, имеющих социальную значимость для государства. Например, это могут быть государственные программы по управлению экологической средой или ориентированные на миграцию населения с целью сокращения уровня бедности на конкретной территории страны. Зачастую последствия таких проектов трудно предсказать в краткосрочном аспекте. Очевидно, что в этом случае проводить непосредственный аудит текущих мероприятий в режиме реального времени смысла не имеет - для государственных программ такого масштаба особое значение приобретают аудиты будущих периодов;

- разнообразием методов аудита. Гибкость в подходах к аудиту напрямую увязывается с многообразием его содержания (самих предметов аудита). В процессе аудита эффективности могут использоваться не только традиционные методы, такие как метод последовательного расследования и метод обратного расследования, но и новые методики (например, метод анализа и метод аргументации).

\section{Основное содержание и чели аудита эффективности}

Цели аудита эффективности. В законодательстве КНР цели аудита эффективности четко не определены. В этом смысле можно выделить три группы аудиторских задач:

3 Вэй Хунчжэн (魏红征). Анализ сходства и различий между оценкой деятельности правительства и аудитом эффективности = 政府绩效评价与绩效审计异同性探析 // Бухгалтерские коммуникации. 2019(10). C. 115-119. 
- проведение независимой аудиторской проверки того, насколько проверяемая организация экономически эффективно проводит установленную для нее политику;

- формирование отчета о том, в какой степени проверяемые в рамках независимой аудиторской проверки лица и хозяйствующие субъекты достигают поставленных перед ними целей, и предоставление соответствующих оценочных заключений органам, принимающим решения;

- выявление и анализ признаков недостаточной экономической результативности объекта аудита в целом или дифференцированно по направлениям его профильной деятельности, с целью помочь проверяемому хозяйствующего субъекту оптимизировать свою работу.

Основное содержание аудита эффективности. Содержание аудита эффективности определяется разными исследователями с разной степенью широты. Классификаций того, что следует понимать под содержанием аудита эффективности, также существует немало.

Так, Ли Вэй считает, что аудит эффективности в КНР можно разделить на два основных подвида - аудит доходов и аудит расходов: первый вид - это аудит эффективности бюджетных доходов. Фокусируясь на проверке финансовых доходов государственных ведомств, аудит эффективности играет важную роль в надзоре за тем, соответствует ли получение государственных финансовых доходов требованиям приобретения ресурсов и требованиям уместности и законности. Как поясняет Ли Вэй, «...процесс сбора платежей отделом по сбору бюджетных средств также относится к сфере использования ресурсов для выполнения своих обязанностей и должен использоваться в качестве содержания аудита эффективности».

Второй вид - это аудит эффективности бюджетных расходов ${ }^{4}$. Бюджетные расходы представляют собой использование государственных средств, находящихся под управлением государства, и содержание аудита эффективности в этом случае состоит в том, чтобы проверить, насколько эффективно используются эти средства и отвечает ли режим их использования потребностям общества (очевидно, что государственное финансирование, так или иначе, воздействует на многие сферы общественной жизни - функционирование общественных организаций, коммунальной и транспортной инфраструктуры, государственных предприятий и пр.).
Китайский исследователь Ли Янь выделяет три составных части аудита эффективности:

- оценку продуктивности и результативности государственных органов и учреждений в контексте финансовых доходов и расходов;

- оценку рациональности, стандартизации и эффективности общественного инженерного строительства;

- оценку эффективности различных административных действий 5 .

Также аудит эффективности может рассматриваться в трех плоскостях - аудита эффективности государственных ведомств, аудита эффективности государственных проектов и аудита эффективности государственных ресурсов.

Aудит эффрективности государственных ведомств ориентирован на оценку эффективности государства или государственных учреждений. Аудит эффективности государственных проектов предназначен для контроля эффективности выполнения государством своих обязанностей по отношению к обществу, при этом в качестве содержания аудита рассматриваются инвестиционные проекты, финансируемые государством. Aудит эфрфективности государственных ресурсов в основном оценивает экономичность, продуктивность и результативность использования раличными учреждениями и ведомствами средств, выделяемых им государством.

\section{Практическое значение аудита эффективности}

Поскольку в конечном счете аудит эффективности направлен на повышение качества самого процесса управления государственными ресурсами за счет предоставления полной, достоверной и объективной информации об эффективности функционирования органов власти и организаций, вовлеченных в бюджетный процесс, то его практическое значение выражается в том, что эта процедура является:

- необходимым условием для создания эффективного правительства;

- ключевым фактором эффективного использования ограниченных ресурсов;

- фундаментальной основой защиты интересов общества в целом, а также прав и свобод все его граждан в отдельности;

- важнейшим требованием обеспечения национальной безопасности (в экономическом и социальном планах);

- залогом устойчивого социально-экономического развития государства.

4 Ли Вэй (李伟). Обзор исследования по государственому аудиту эффективности =政府绩效审计问题研究综述 // Справочник по экономическим исследованиям. 2018(36). С. 44-55; 2018(36). С. 44-55.

5 Ли Янь (李燕), Чжан Сян (张翔), Чжан Вэйхун (张围红). Исследование реформы государственого аудита эффективности в Китае =中国政府绩效审计改革研究 // Журнал Юньнаньского университета финансов и экономики. 2018. 34(04). С. $104-112$. 
Проблемы развития аудита эффективности в КНР

Наиболее актуальной в настоящее время является проблема низких темпов развития и совершенствования системы аудита эффективности в Китайской Народной Республике. Нужно сказать, что научно-теоретическая база начала формироваться еще несколько десятилетий назад - в то время в КНР был опубликован целый ряд документов, регламентирующих процедуру оценки эффективности, - «Система показателей оценки эффективности предприятия» (1995), «Правила оценки эффективности государственного капитала» и «Правила проведения оценки эффективности государственного капитала» (1999). Все эти работы имели и имеют определенную ценность (прежде всего справочную) в том числе для методологии аудита эффективности.

На сегодняшний день систему государственного аудита эффективности в КНР составляют стандарты аудита эффективности, система оценочных индексов и перечень руководящих принципов аудиторской деятельности. Однако система аудита эффективности все еще не выглядит завершенной - не разработан национальный стандарт этого вида аудита, нет пока национального руководства по его процедуре, отсутствует национальная система показателей аудита эффективности. Все это серьезно тормозит прогресс в теории и практике аудита эффективности в КНР.

Следующая проблема - недостаточно широкое содержание самой оценки аудита эффективности. После более чем десяти лет работы в этом направлении содержание оценки аудита эффективности претерпело изменение с начального «2Е» (экономичность и продуктивность) до «5Е» (экономичность, продуктивность, результативность, справедливость и экологичность). В то же время некоторые страны мира пошли еще дальше, официально включив в содержание оценки аудита эффективности и такую категорию, как «этика». Таким образом, сегодня речь уже идет о формате аудита «6Е». При этом, по сути, в КНР аудит эффективности, проводимый государственными аудиторскими учреждениями, в основном сосредоточен на оценке экономичности, продуктивности и результативности использования государственных средств, то есть, содержание оценки редко выходит за рамки концепции «3Е».

И, наконец, третье препятствие - несовершенство системы показателей оценки аудита эффективности. Дело в том, что государство как полисистемный объект ежегодно генерирует огромный объем данных и разнородной информации, которую нужно структурировать, фильтровать и своевременно «загрузить» в систему национального аудита эффективности. Эти задачи призвана решать система показателей оценки аудита эффективности, которая все еще далека от идеальной. Она постоянно до- рабатывается и корректируется и все же по-прежнему не во всем отвечает требованиям современности. Кроме того, эта система страдает и определенными перекосами структуры (к примеру, существует проблема уделения слишком большого внимания индексу фактического контроля).

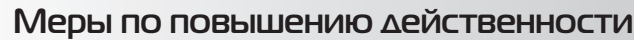 аудита эффективности}

В качестве мер повышения действенности аудита эффективности можно рассматривать модернизацию концепции аудита эффективности, его системы оценочных показателей, а также соответствующей нормативной правовой базы.

Инновационные концепции эффективности и технические методы их реализации. Аудит эффективности - это новый этап в развитии государственного аудита, это важный шаг на пути углубления реформы административной системы страны (в данном случае речь идет о КНР). Аудит эффективности способствует прогрессивному преобразованию системы государственного управления, росту качества государственных услуг и повышению эффективности управления государством. Аудиторские учреждения должны осознавать важность процедуры аудита эффективности и активно внедрять в свою деятельность новые информационные технологии (методы работы с большими массивами данных - BigData блокчейн-технологии), а также разрабатывать и активно применять современное программное обеспечение и аудиторские методики.

Формирование полноценной системы показателей оценки аудита эффективности. Оценочные показатели аудита эффективности должны быть научно обоснованными и рациональными. Для этих целей в регионах должны в полной мере использовать научноисследовательский потенциал местных высших учебных заведений. Взаимодействие вузов с аудиторскими учреждениями и другими государственными структурами в целях организации семинаров, проведения презентаций и консультаций должно быть повсеместным. Использование возможностей третьей стороны для оценки показателей аудита эффективности, на наш взгляд, может значительно обогатить научные исследования в области систематизации показателей оценки аудита эффективности, что позволит сохранить за Китаем место в авангарде мирового общественного развития. В то же время не стоит замыкаться исключительно на теоретических разработках, делая акцент на обмене опытом в сфере практической деятельности.

Совершенствование нормативной правовой базы. Развитие аудита эффективности должно быть гарантировано действующими законами, адекватной 
системой норм и правил. С одной стороны, следует улучшить законотворческую деятельность, связанную с аудитом эффективности, придать аудиту эффективности необходимое юридическое подкрепление, уточнить статус этой процедуры. С другой стороны, нужно установить всеобщий стандарт аудита эффективности для национальных аудиторских учреждений, для того чтобы унифицировать контроль качества аудиторских процедур, регламентировать порядок проведения аудита, а также обобщить и описать объекты, цели, оценки и методики применения аудитов эффективности.

\section{ЗакАючение}

Аудит эффективности является важным инструмен- том измерения эффективности деятельности правительства страны. В Китайской Народной Республике аудит эффективности все еще находится в стадии становления, хотя его концепция постоянно совершенствуется. Дальнейшее развитие методики аудита эффективности требует совместных усилий теоретиков и практиков государственного управления в целях рационального и научно обоснованного распределения имеющихся ограниченных ресурсов в рамках существующей социально-экономической модели. Однако аудит эффективности - это не только орудие контроля, его конечная цель - реально способствовать повышению качества жизни рядовых граждан, сделать экономику страны более устойчивой к внешним вызовам.

\section{ЛИТЕРАТУРА}

1. Ван Гуанюань (王光远), Чжэн Сяоюй (郑晓宇). 政府审计移送对司法效率的影响 / Влияние передачи государственного аудита на эффективность судебной системы // Исследование аудита. 2019(4). С. 11-19.

2. Ма Дуншань (马东山), Хань Лянлян (韩亮亮), Чжан Шэнцян (张胜强). Государственный аудит может уменьшить задолженность местных органов власти. Рост - перспектива фискальной децентрализации = 政府审计能够抑制地方政府债务增长吗? - 财政分权的视角 // Аудит и экономические исследования. 2019 (4). С. 9-21.

3. Вэй Хунчжэн (魏红征). Анализ сходства и различий между оценкой деятельности правительства и аудитом эффективности=政府绩效评价与绩 效审计异同性探析 // Бухгалтерские коммуникации. 2019(10). С. 115-119.

4. Ли Вэй (李伟). 0бзор исследования по государственному аудиту эффективности =政府绩效审计问题研究综述 // Справочник по экономическим исследованиям. 2018(36). С. 44-55; 2018(36). С. 44-55.

5. Ли Янь (李燕), Чжан Сян (张翔), Чжан Вэйхун (张围红). Исследование реформы государственного аудита эффективности в Китае = 中国政府绩 效审计改革研究 //Журнал Юньнаньского университета финансов и экономики. 2018. 34(04). С. 104-112.

6. Чжан Цзюань (张娟). Исследование аудита эффективности правительства с точки зрения нового государственного управления = 新公共管理视角 下政府绩效审计研究 // Форум рынка. 2019(01). C. 52-54.

7. Бычкова, С.М. Аудиторская деятельность. Теория и практика / С.М. Бычкова. М.: Лань, 2018. 320 с.

8. Тишуков, Ю.В. Все о проверках: надзор и контроль / Ю.В. Тишуков. М.: Феникс, 2020. 268 с.

9. Терехов, А.А. Аудит: перспективы развития / А. А. Терехов. М.: Машиностроение, 2017. 560 с.

10. Кобозева, Н.В. Противодействие легализации (отмыванию) доходов, полученных преступным путем, и финансированию терроризма в аудиторской деятельности / Н.В. Кобозева. М.: Магистр, Инфра-М, 2019. 128 с.

() Лю Яли (18193158922@163.com). 